\title{
MADRES E HIJOS ENAMORADOS. LA SUBLIMACIÓN DE LA RELACIÓN MATERNAL EN LOS LIBROS DE LECTURA ESPAÑOLES Y COLOMBIANOS EN LA PRIMERA MITAD DEL SIGLO XX ${ }^{\S}$
}

\author{
Mothers and children in love. The sublimation of the maternal \\ relationship in Spanish and Colombian textbooks in the first half \\ of the twentieth century
}

\section{Federico Guillermo Serrano López*}

Fecha de recepción: 08/02/2015 • Fecha de aceptación: 05/05/2015

Resumen. Entre los textos escolares de la primera mitad del siglo XX, los libros de lectura para primaria fueron protagónicos en la intervención de los afectos infantiles. En ellos se tendió a idealizar la relación amorosa madre-hijo. El artículo se ocupa de examinar las manifestaciones de esta idealización en la configuración ideal de los sujetos «mujer», «hijo»e «hija»; y en las descripciones que se encuentran de la emoción amorosa en estos manuales.

A partir del análisis de noventa libros de lectura del periodo, en los dos países, se hace una lectura genealógica, en la perspectiva foucaultiana, de la configuración de unos tipos ideales de subjetividad presentes en las estrategias educativas de estos textos.

Se encontró allí que el objeto amoroso por antonomasia fue la madre y a ella fueron dirigidas las expresiones físicas e intelectuales del amor llamado puro e incondicional. En las muestras del comportamiento de las mujeres adultas, a su vez, es únicamente hacia los hijos e hijas que expresan intensos deseos de caricias y de expresiones románticas de amor incondicional, y no hacia los esposos u otros adultos.

Concluyo que esta relación amorosa sirvió para definir la estructura de la biografía femenina, el papel de las mujeres en el hogar, las conductas lícitas

\footnotetext{
$\S$ El presente artículo es resultado de la investigación doctoral del autor, titulada Formar padres y madres. La preparación para la sexualidad en los manuales escolares en España y en Colombia entre 1930 y 1960, dirigida por los profesores Juana Sánchez-Gey, de la Universidad Autónoma de Madrid, y Miguel Somoza Rodríguez, de la Universidad Nacional de Educación a Distancia.

* Facultad de Ciencias Sociales y Humanas, Universidad Tecnológica de Bolívar. Km. 1, vía Turbaco. Cartagena. Colombia. fserrano@unitecnologica.edu.co
}

Cómo citar este artículo: Serrano López, Federico Guillermo. «Madres e hijos enamorados. La sublimación de la relación maternal en los libros de lectura españoles y colombianos en la primera mitad del siglo XX», Historia y Memoria de la Educación, 2 (2015): 219-237. 
de todos los miembros de la familia y su sentido existencial. Asimismo, esta relación alentó la configuración de una economía de los deseos y placeres ordenada a la estabilidad familiar y social a partir de un sentimiento de lealtad incondicional cuyo modelo era el amor por la madre.

Palabras clave: Emociones. Familia. Madre. Mujer. Manuales escolares.

Abstract. In the first half of the XX century, primary school textbooks played a prominent role in the molding of children's emotions and their affective relationships. Spanish and Colombians textbooks published at that time commonly idealized the mother-child relationship. This paper examines the manifestations of this idealization in the configuration of the subjects «mother» and "child», and in the depictions of the emotion of love in these textbooks.

Based on the analysis of ninety reading textbooks from this period, from both countries, a genealogical reading has been made, from a Foucaultian perspective, of the configuration of some ideal types of subjectivities present in the educational strategies of these texts.

In the texts, it was found that the main object of love was the mother and that it was to her whom children exclusively directed the physical and intellectual expressions of a so called pure and unconditional love. Furthermore, in terms of the behavior of adult women, expressions of physical tenderness and expressions of romantic and unconditional love were directed exclusively toward children, and not toward a spouse or other adults.

It was concluded that this love relationship served to define the basic structure of the feminine biography, the role of women at home, the licit behavior of family members and their existential purpose. This relationship also promoted the configuration of an economy of desire and pleasure directed toward the stability of family and society based on a feeling of unconditional loyalty whose model was the love for the mother.

Keywords: Emotions. Family. Mother. Woman. Textbooks.

\section{INTRODUCCIÓN}

Uno de los aspectos centrales del proyecto educativo de inicios del siglo XX en relación con la formación de la subjetividad ${ }^{1}$ consistió en el intento delibe-

\footnotetext{
${ }^{1}$ Siguiendo el modelo conceptual de Michel Foucault, entendemos por formación de la subjetividad los dispositivos de poder por medio de los cuales los agentes de poder buscan que un individuo asuma una identidad; que es en parte impuesta por las expectativas de otros, y en parte asumida por el mismo individuo, con base en el auto-conocimiento que va adquiriendo de sí mismo. Por ello se habla del sujeto como aquel que está sujetado en dos sentidos, de una parte, sometido al control y las expectativas de otros, y de otra, atado a la idea que él mismo va adquiriendo de sí mismo. Confrontar: Michel Foucault, «El sujeto y el poder», en Hubert L. Dreyfuss y Paul Rabinov, Michel Foucault: más allá del estructuralismo y la hermenéutica (Buenos Aires: Ediciones Nueva Visión, 2001), 241-259; Raul Anzaldúa «La
} 
rado por formar las emociones de los niños de forma favorable al orden social en los aspectos que los agentes educadores consideraban claves: las reacciones emocionales frente al bien y el mal, el respeto a los valores tradicionales y, sobre todo, la formación de un vínculo afectivo entrañable con las estructuras sociales. En el presente artículo se muestra cómo el núcleo desde el cual se estructuró la red de sentimientos pasionales favorables hacia el orden social se buscó que estuviera en la relación amorosa madre-hijo. Asimismo, se hace presente de qué modo esta relación permitió caracterizar no solo algunos aspectos definitorios de los roles de género en sus diferentes relaciones con la estructura social sino también la estructura normativa de las emociones del sujeto. Esto es, los medios con los que se expresaba a las personas qué se debía sentir para ser «mujer», «madre», «hijo», «hija», «bueno» o «patriota».

Este trabajo busca contribuir dentro del campo de estudio de las emociones y los sentimientos en la historia de la educación. Particularmente en uno de los aspectos que, en un intento por caracterizar el campo, ha descrito la profesora Mahamud: «buscar, rescatar y desenmascarar las emociones y los sentimientos plasmados o camuflados que subyacen en los discursos y textos de los planes, proyectos, programas y documentos educativos: legislación, currículo y recursos didácticos». ${ }^{2}$ Del mismo modo, pretende ampliar la comprensión en torno de los contenidos y expresiones de la «educación de las mujeres» en los dos países; ${ }^{3}$ específicamente mostrar unas manifestaciones ejemplares de las formas concretas y del lenguaje con el que los agentes educadores buscaron con la educación en general, pero más concretamente con la educación de las mujeres, afianzar el vínculo entre la nación y la familia, lo que permitió que las mujeres se convirtieran en «asociadas imprescindibles para los procesos de gobierno de la vida distintivos de los Estados modernos». ${ }^{4}$

formación: una mirada desde el sujeto», en Memoria electrónica X Congreso Nacional de Investigación Educativa, área temática 15 (México D.F.: Consejo Mexicano de Investigación Educativa A.C., 2009). http://www.comie.org.mx/congreso/memoriaelectronica/v10/pdf/area_tematica_15/ponencias/0251-F.pdf (consultado el 19-1-2015).

2 Kira Mahamud, «Emociones y sentimientos: coordenadas históricas y multidisciplinares de un campo de estudio clave», Avances en Supervisión Educativa. Revista de la Asociación de Inspectores de Educación en España, 16 (2012): 13. http://www.adide.org/revista/images/stories/pdf_16/ase16_mono02.pdf (consultado el 19-1-2015).

${ }^{3}$ Confrontar: Zandra Pedraza, «La "educación de las mujeres": el avance de las formas de modernidad en Colombia», Revista de Estudios Sociales, 41 (2011): 72-83, y Teresa González, "Enseñando a ser mujeres: literatura para niñas en la historia de la educación», History of Education \& Children's Literature, IV (1), (2009): 95-112.

${ }^{4}$ Pedraza, «La "educación de las mujeres"», 78. 


\section{FUENTES Y MÉTODO DE INVESTIGACIÓN}

Sobre las fuentes, es preciso anotar que, junto con los catecismos, el libro de lectura fue el tipo de manual escolar de mayor desarrollo e impacto al iniciarse el siglo XX, tanto en España como en Colombia. ${ }^{5}$ Consistieron, por una parte, en los libros básicos de iniciación a la lectura (cartillas y silabarios) que, además de ofrecer los métodos para aprender a leer, en las mismas frases elementales que usaron como ejemplos revelaban formas de relacionarse el niño con los posibles objetos de deseo, además de proveer algunas reglas muy elementales de conducta y ejemplos básicos de buen y mal comportamiento; de otra parte, también pertenecían a esta categoría los textos dedicados a la lectura comprensiva, normalmente graduados, ejemplarizantes y moralizadores, con los cuales se ejercitaba a los niños a leer de corrido, en voz baja y alta; así como los manuscritos, textos en los que los niños practicaban el reconocimiento de los diferentes tipos de caligrafía con pluma (frecuentes en España, pero inexistentes en Colombia).

En todos estos textos, además del propósito pedagógico de alentar el ejercicio de la lectura, llevaban en sus contenidos toda suerte de historias, poemas, descripciones y ejemplos de personajes y actividades cargadas de un fuerte contenido moral. Algunos de ellos son colecciones de trozos escogidos de varios autores considerados adecuados para presentar a los niños ejemplos de los escritores nacionales o internacionales. Sin embargo,

\footnotetext{
${ }^{5}$ Sobre manuales escolares en España, confrontar: Agustín Escolano (dir.) Historia ilustrada del libro escolar en España. Del Antiguo Régimen a la Segunda República (Madrid: Fundación Germán Sánchez Ruipérez, 1997) e Historia ilustrada del libro escolar en España. De la postguerra a la reforma educativa, (Madrid: Fundación Germán Sánchez Ruipérez, 1998); Alejandro Tiana Ferrer, «La investigación histórica sobre los manuales escolares en España: el Proyecto Manes», Revista Clío y Asociados. La historia enseñada, 4 (1999): 101-119; José María Hernández Díaz, «Espacios escolares, contenidos, manuales y métodos de enseñanza.», en Historia de la educación en la España contemporánea. Diez años de investigación, ed. Jean Louis Guereña, Julio Ruiz Berrio y Alejandro Tiana Ferrer (Madrid: Ministerio de Educación y Ciencia. C.I.D.E., 1994), 191-213; Alejandro Tiana Ferrer (ed.), El libro escolar: reflejo de intenciones políticas y de influencias pedagógicas (Madrid: UNED, 2000); José Luis Villalaín, Manuales escolares en España (Madrid: UNED, 1997-1999-2002, 3 vols.). Sobre manuales escolares en Colombia confrontar: Gabriela Ossenbach y Miguel Somoza (eds.) Los manuales escolares como fuente para la historia de la educación en América Latina. (Madrid: UNED, 2001); Jorge Conde Calderón et al, Nación, educación, universidad y manuales escolares en Colombia: tendencias historiográficas contemporáneas / IV coloquio colombiano de historia de la educación, Barranquilla, sep. 6-8 de 2001 (Barranquilla: Fondo de Publicaciones de la Universidad del Atlántico, 2001); Jean-Louis Guereña, Gabriela Ossenbach y María del Mar del Pozo (dirs.), Manuales escolares en España, Portugal y América Latina (siglos XIX y XX) (Madrid: UNED, 2005); Cecilia Rincón Verdugo, La enseñanza de la lectura y la escritura en Colombia, 1870-1936. Una mirada desde la práctica pedagógica. (Bogotá: Universidad Distrital Francisco José de Caldas, 2003).
} 
también se encontró una muy importante cantidad de textos producidos específicamente para los libros de lectura, e incluso hubo algunos autores especialmente reconocidos en la elaboración de textos de este género literario escolar.

El propósito explícito de una importante cantidad de ellos es conseguir la formación moral por medio de dirigirse a la afectividad infantil, menos en la forma de prescripciones normativas (aunque no faltan ejemplos de estas reglas en algunos textos) y más en la forma de ejemplos de personajes con los cuales se pretendía que el niño se identificara. De estos textos se encuentra una gran variedad de estilos que varían de acuerdo con épocas y autores, especialmente en España. En Colombia hubo un número importante, aunque significativamente menor que el español, de libros de lectura; es de destacar, sin embargo, que a partir de 1930 se dio el predominio en el uso de uno de estos manuales sobre todos los demás: La alegría de leer, del pedagogo vallecaucano Evangelista Quintana, que empezó a ser editado por la Editorial Voluntad en 1930 y cuya 61 edición se publicó en 1980, aunque su uso generalizado disminuyó al finalizar la década del sesenta.

Nos concentramos en los libros de lectura precisamente porque en ellos se tiende a expresar los mensajes de manera implícita y tangencial. Es frecuente que se dé en ellos, por medio de sus historias, poemas y moralejas, un rodeo a los objetivos que persiguen. En ese sentido, su cometido ideológico es más ambiguo, pero precisamente por ello, más rico y pretendidamente más eficaz para producir una reacción emotiva en los sujetos a los que se dirige.

Entre la enorme cantidad de títulos de manuales escolares que cumplen con las características anteriores ha sido necesario distinguir entre ellos los que tuvieron una mayor relevancia y representatividad entre el final del siglo XIX y la primera mitad del siglo XX en España y Colombia. Se seleccionaron entonces noventa manuales de los dos países a los que se interrogó sobre la relación madre hijo. ${ }^{6}$ Para esta selección se aplicaron varios criterios simultáneos: en primer lugar, la pertenencia del manual al fondo de las editoriales más reconocidas en la época; en segundo

\footnotetext{
${ }^{6}$ Esta interrogación cubrió otros muchos temas relacionados con la preparación para la sexualidad, pero se presentan en este trabajo los aspectos específicamente relacionados con el tema del artículo. Es de anotar que, si bien en el presente texto solo se han extraído citas de unos pocos de estos noventa manuales, las caracterizaciones generales se hicieron teniendo en cuenta toda la base documental.
} 
lugar, el número de ediciones del mismo manual encontradas a lo largo del periodo; en tercer lugar, el prestigio del autor y la relativa abundancia o escasez de títulos del mismo autor; en cuarto lugar, el hecho de ser recomendados por alguna autoridad importante respecto del tema en la época, como los inspectores escolares, las autoridades eclesiásticas o los mismos maestros. ${ }^{7}$ En cuanto a la dirección específica que se le dio al estudio de las lecturas analizadas se atendió, en lo que tiene que ver con el tema del presente artículo: a los objetos por los que se manifestaba amor y aprecio, particularmente las personas, aunque también las instituciones y sentimientos; a las menciones y caracterizaciones literarias o gráficas de los personajes analizados: «madre», «hija», «hijo», «niña»y «niño»; y, por último, a las relaciones manifiestas entre las personas e instituciones estudiadas.

La lectura de estos textos se hizo en la perspectiva genealógica foucaultiana en la medida en que se ve en estos textos los elementos germinales del presente, y se examinan como unos elementos significativos dentro de un paisaje más complejo que configuró la emergencia de los sujetos que pueblan las sociedades contemporáneas. En el caso particular que nos ocupa esta lectura es un aporte para examinar algunas sujeciones fundamentales de los sujetos niña, madre, mujer, hijo, padre y esposo.

Antes de ir al análisis propiamente tal es pertinente aclarar que, como bien señala el profesor José Seoane, ${ }^{8}$ si bien la mayoría de estos trabajos que se basan en los manuales escolares no permiten penetrar el modo como estos textos fueron leídos, o el grado de influencia que ellos tuvieron en sus lectores, sí permiten vislumbrar los modelos con los cuales, y, en algunos casos, contra los cuales, se configuró simbólicamente la subjetividad de muchos niños que recibieron su educación primaria en la primera mitad del siglo XX. Por lo tanto, estos textos informan al menos sobre las intenciones educativas de los agentes educadores, y de un modo indirecto, que hay que leer entre líneas, sobre los propósitos de la formación.

\footnotetext{
${ }^{7}$ Para este propósito, particularmente respecto de los libros de lectura del periodo de la dictadura franquista, es especialmente útil el texto de Francisca Montilla, Selección de libros escolares de lectura (Madrid: CSIC, 1954), libro en el que expone los resultados de una encuesta que esta inspectora escolar realizó, entre profesores e inspectores, respecto de los libros de lectura preferidos por ellos.

${ }^{8}$ José Seoane, El placer y la norma. genealogía de la educación sexual en la España contemporánea. Orígenes (1800-1920) (Barcelona: Ediciones Octaedro, 2006), 20.
} 


\section{RESULTADOS}

\section{El amor al interior de la familia y su extrapolación a la sociedad}

Uno de los elementos más recurrentes del tratamiento de los personajes que aparecen en las lecturas de los textos seleccionados es la tendencia a que se diluya en ellos la condición de individuos con identidad, deseos y placeres propios para que predomine en ellos su carácter de miembros de una familia; es decir, los personajes de las historias dedicadas a los niños son antes y principalmente hijos, hermanos, padres o abuelos y encuentran en esos rolles la plenitud de su subjetividad; en cambio, cuando en las historias se afirma de algún modo la individualidad, sobre todo cuando entra en contradicción con los intereses colectivos, se la censura con dureza. Se hizo patente, asimismo, que uno de los elementos decisivos, a lo largo de todo el periodo, que sirvió de motivación para afianzar este modelo de subjetividad que enfatizó la condición de miembro de una familia, es la representación de la familia, y del ambiente familiar, como la fuente principal de los goces no solo lícitos, sino de los que son presentados como reales. Los otros, los goces llamados egoístas, tienen un carácter ilusorio y transitorio que los hace ser considerados como falsos.

En coincidencia con la observación de Badanelli, ${ }^{9}$ encontramos que los goces familiares están asociados principalmente al sosiego y la alegría y el hogar es, simbólicamente, el espacio que le corresponde plenamente a los sujetos para su expansión y disfrute: «iQué gusto, qué regusto da sentir ese calorcillo de hogar de estar todos juntos queriéndose tanto [...] Calor de hogar, bendito calor de hogar, iqué felices son los niños que lo sienten!». ${ }^{10} \mathrm{Y}$ así, en los libros de lectura (a lo largo de todo el periodo, en los dos países) se muestra a niños, niñas, padres y madres gozando en mutua compañía en conversaciones educativas, excursiones al campo, celebraciones familiares, fiestas patrias compartidas en familia, etcétera. En cambio, la taberna, el garito, el burdel, los teatros y salas de cine se presentan como diversiones costosas, dañinas para la moral y la salud, y causa de dolorosos arrepentimientos.

La justificación de tanta alegría y goce al interior de la familia es el amor que reina en su interior, el cual es generoso y sacrificado, coherentemente

\footnotetext{
9 Ana María Badanelli, «Emociones e imágenes en la construcción de las identidades de género», en $L a$ infancia en la historia: espacios y representaciones, eds. Paulí Dávila y Luis María Naya (Donostia: Eiren, 2005), 287.

10 Josefina Álvarez, Hermanitos (Madrid: Magisterio Español, 1948), 99.
} 
con la idea de realizarse subjetivamente a través del bien colectivo. En tal sentido es interesante poner en alto que una de las lecturas que mayormente se repitió en diferentes manuales de ambos países, atribuida a diferentes autores, con pequeñas variaciones en cada versión, fue la de una familia feliz en la cual todos sacrifican su gozo individual por el amor que sienten por los miembros de su familia:

A una madre de familia le regalaron un racimo de uvas, y se lo dio a su hija Clotilde, niña de pocos años. Clotilde pensó que agradaría a su hermano comer aquel fresco racimo, y se lo llevó al taller. El muchacho agradeció la fineza; pero viendo a su padre trabajar en un campo inmediato, corrió a ofrecerle el racimo. Lo recibió el padre con placer; pero acordándose de que su mujer agradecería el obsequio, se lo llevó a la casa por la tarde.

Cuando la madre volvió a ver en sus manos el racimo de uvas, dio gracias al cielo por el entrañable amor que reinaba en su familia.

La felicidad de la familia está en el amor que se profesan los miembros que la constituyen. ${ }^{11}$

Como la lectura lo ilustra, el sello del verdadero amor es la disposición al sacrificio y la abnegación. El sujeto amante debe poner en último lugar sus deseos, e incluso sus expectativas sobre el futuro, como implícita y explícitamente se les exige particularmente a las mujeres. ${ }^{12}$ La satisfacción por excelencia es, por tanto, la que da el servicio y la generosidad, no solo al interior de la familia, sino hacia la sociedad en la forma de caridad desinteresada, que es la virtud más frecuentemente encomiada a lo largo de todo el periodo acotado, pero sobre todo en los textos escritos a finales del siglo XIX e inicios del XX. Así, los sujetos mayormente dignos de amor no son los más bellos, inteligentes o interesantes, sino los que más han sufrido o se muestran mayormente aptos para el sacrificio. Este criterio se aplica principalmente para la elección del cónyuge, pero también para la selección de las amistades, de los trabajadores, de los soldados y de los gobernantes.

El amor sacrificado forma, por lo tanto, el vínculo fundamental de toda la sociedad, comienza en la familia, pero se extiende desde ella hacia la escuela, el barrio, la ciudad, el país, la iglesia y, por último hacia la huma-

\footnotetext{
${ }^{11}$ Ezequiel Solana, Lecturas infantiles. Primer libro de lectura corriente (Madrid: Escuela Española, ¿1900?), 33-34.

12 Teresa González, «Enseñando a ser mujeres», 105.
} 
nidad, ámbito en donde el modelo se vincula nuevamente con el amor sacrificial de Cristo por toda la familia humana. Sin embargo, el fundamento de todo el proceso está en la relación amorosa con la madre y es allí en donde los libros de lectura expresan de forma más intensa y explícita lo que pretenden que es una realidad cultural; en consecuencia, es también este el punto nodal donde se hacen los mayores esfuerzos para intervenir la afectividad infantil, particularmente la de los niños más pequeños.

\section{La relación amorosa de madres e hijos}

En la relación amorosa madre-hijo es indispensable explorar, en primer lugar, la ambigüedad romántica con la que suelen describirlo. En numerosas ocasiones madre e hijo se comportan con gestos de amor romántico. Dice, por ejemplo, en el libro de lectura Para mi hijo:

- Dime, luz de mis ojos, corazoncito mío, ¿quieres que me esté a tu lado?

- Sí, madre; que te quiero mucho; y al mirarme tú, creo que me pongo bueno. (...)

- ¿Me quieres mucho, madrecita?

— ¡Muchísimo!... ¡No te puedes dar idea, Luisín!13

En este ejemplo y muchos otros por el estilo, frecuentes en los textos del final del siglo XIX y en los de las primeras décadas del siglo XX y un poco menos en los libros escritos hacia el final, la madre es para el hijo simbólica y realmente la mujer de su vida y su objeto amoroso privilegiado por encima de todos los demás seres, incluidos allí el padre, e incluso Dios, que son el objeto de otro tipo de amor. En el espectro del amor pasional del hijo la madre reina indiscutiblemente. A la inversa, el hijo es para la madre el principal hombre en su vida y su amor es presentado con toda la desmesura de un apasionamiento romántico sublimado por la total abnegación y desinterés que define la relación:

[El niño tenía sueño] «Y la madre, cariñosa, tomando el niño en los brazos, lo meció sobre su mullida falda, lo arrulló con inefable ternura, entre besos y cantares, y sonriente y tranquilo..., el angelito se durmió...

\footnotetext{
${ }^{13}$ Mateo Bustamante, Para mi hijo (Burgos: Hijos de Santiago Rodríguez, ¿1920?), 3-4.
} 
Solícita la madre entonces, fue desnudando a su hijo, hízole con reverencia la señal de la cruz, imprimióle un dulcísimo beso de amor y le acostó.

¡Qué hermoso estaba el niño!

Ella, que lo contemplaba, sin acertar a separarse de su lado, se arrodilló al borde de la cuna con respetuoso silencio, le volvió a arreglar la ropita, le besó con la dulce ternura que saben besar las madres y elevó al cielo una sentidísima plegaria por el bien de aquel tierno pedazo de su corazón...

De pronto sonrió el niño, como si quisiera mostrar a su madre gratitud, y, llena de júbilo, la madre prorrumpió:

- Ángel mío!... Duerme y ríe.

$\mathrm{Y}$, como si quisiera beber de aquellas angelicales sonrisas, besó repetidas veces los labios puros de su hijo, colmándolo al mismo tiempo de cariñosas expresiones. ${ }^{14}$

Teniendo esta relación un peso tan grande es frecuente que se afirme que el hijo es todo para la madre, lo que justifica el hecho de que ella esté dispuesta a diluirse totalmente en esa relación, con indiferencia frente a la posible ingratitud del hijo. La abnegación desinteresada convierte a la madre en una heroína, pero también le debería garantizar el amor incondicional del objeto de su afecto y, efectivamente, el que no demuestra corresponder a ese amor es señalado como un monstruo afectivo y moral.

El hombre que permanece insensible ante la mirada de su madre, que no siente el escalofrío de la ternura ante sus palabras y no advierte que se le rasga alguna entretela en el fondo del alma, cuando su madre llora por alguna ingratitud filial... más le valiera no haber nacido, porque es un hombre sin corazón, y es lo mismo que un paisaje sin cielo, y un templo sin Eucaristía.

La grandeza de los seres amados se mide por el sufrimiento, que es la forma del amor en las escenas de la vida; y si esto es así, no hay nada más grande que el corazón de una madre, que parece nacida para sufrir, como si el martillo del dolor fuese forjando, para la eternidad, ese precioso relicario de oro puro y acrisolado que llamamos corazón de madre.

\footnotetext{
${ }^{14}$ Ezequiel Solana, Lecturas de oro (Madrid: Escuela Española, ¿1901?), 48.
} 
Desde los orígenes del mundo, en que la madre siente muy honda la mordedura del remordimiento, al estrechar el ensangrentado cadáver de Abel, mientras el fratricida huye despavorido, sin hallar espesuras ni sombras que le oculten a la mirada de Dios, hasta las heroínas de nuestros días, sacrificando sus amores en aras de la resignación cristiana y en el glorioso altar de la Patria, se puede decir que la madre funda sus glorias en sufrir por sus hijos, sin aspirar a más recompensas que una mirada y una sonrisa de cariño. ${ }^{15}$

El hijo, por su parte, solo en su madre encuentra el único amor en el que puede confiar, precisamente por la postulación de la generosidad y el desinterés que se halla a su base. Sin embargo, ¿por qué es este un amor desinteresado? Las respuestas las buscan los libros analizados en la religión y en la naturaleza. Así, de un lado, Dios creó a la mujer para ser madre, es lo que la hace mujer y lo que le da su sentido existencial, y está implícito que, sin la maternidad es incomprensible la feminidad. El amor desinteresado de la madre es, por tanto, expresión suprema del amor de Dios a los hombres. $\mathrm{Al}$ respecto es elocuente la mención que en el Libro de lectura panamericano hace Julio Gaitán de las palabras del doctor Antonio Rocha:

La madre - su ser, su misión, su nobleza - es la obra maestra de la vida, es la suprema elación del espíritu, es el testimonio de la existencia de Dios. Quitad el sentimiento maternal, y habréis borrado del universo el soporte de nuestras esenciales acciones. Todo sin él pierde su sentido, su categoría, su fuerza. Porque la madre es la expresión de la fe, y la fe es el único poder edificante y verdadero. Porque la madre es el amor, y el amor es lo único que redime y vivifica. Hay en ella algo de eterno y de absoluto que no perece, que está más allá del inútil abismo del sepulcro, que nada puede destruir. ${ }^{16}$

Desde el punto de vista de la naturaleza, la condición de hembra es sinónimo de maternidad y entonces algunos autores de los libros de lectura mencionan ejemplos de cómo entre los animales la madre pone el interés de sus hijos por encima del suyo y están dispuestas a darlo todo por los hijos, incluida la vida misma, o a padecer cualquier forma de sufrimiento que se

\footnotetext{
15 Lecturas escolares. Grado cuarto (Madrid: Compañía Bibliográfica Española, 1956), 86-87.

16 Julio Gaitán. Libro de lectura. Texto de lectura para uso de los planteles de la República (Bogotá: Santa Fe, 1944), 132.
} 
requiera por el bien de sus crías. En la lectura titulada «La ballena sublimiza el amor maternal» del libro cuarto de La alegría de leer, se narra:

Cuando se arponea a un ballenato — cuenta M. Scoresbry- puede darse por cierto que la madre no tardará en acudir a socorrerle. Pronto, en efecto, asoma en la superficie, se reúne con su hijo, parece incitarle a huir, se coloca debajo de él, cargándoselo en el lomo y se lo lleva. Mientras tanto, el ballenato procura sostenerse, pegado a su madre, soportando el chapoteo del mar. Es muy raro que la ballena abandone a su cría, mientras ésta viva.

En semejantes circunstancias se hace muy fácil arponear a la madre, pues ésta se olvida completamente de sí misma y de su propia seguridad, para no ocuparse más que de salvar a su hijo. Se lanza contra el enemigo, desprecia el peligro, y aún después de ser herida varias veces se queda al lado de su hijo. Cuando le es imposible llevárselo, la ballena es presa de terrible angustia, se agita y bate el mar con violencia, dando estruendosas muestras de dolor y desesperación. ${ }^{17}$

Con esto se pretende mostrar que existe el instinto maternal y que ese instinto supera las determinaciones egoístas. El mismo instinto se postula como existente en las mujeres y no se encontró ningún caso en el que siquiera se manifestara alguna duda por parte de un personaje femenino respecto de su destino como madre; a menos que se tratara de la vocación religiosa, que se muestra como una posibilidad indirecta de ser madre en la medida en que por esa vía las mujeres se convierten en protectoras de la humanidad y esposas de Cristo. Pero el ejemplo del personaje de una mujer adulta que no sea madre por un motivo diferente a que Dios no le dio hijos, o que siquiera insinúe con sus dichos o su comportamiento la posibilidad de no desear hijos, no aparece en ninguno de los libros estudiados; observación en la que coincidimos con González. ${ }^{18}$

Es claro, en consecuencia, que la maternidad constituye esencialmente la identidad del sujeto mujer en los textos analizados y la estructura de la economía de sus deseos y placeres, incluidos los sexuales. No es extraño, por tanto, que se pueda encontrar en la definición del amor maternal, y en la relación madre-hijo, elementos de alguna ambigüedad erótica en los que, tal vez precisamente por la libertad que da el que la relación madre-hijo esté

\footnotetext{
17 Evangelista Quintana, La alegría de leer. Libro cuarto (Bogotá: Voluntad, 1930), 240-241.

18 Teresa González, «Enseñando a ser mujeres», 99.
} 
postulada como libre de sexo, se hace manifestación espontánea de vivencias de placer sensual. Así, por ejemplo, se encuentra en el libro primero de las Lecturas graduadas, el siguiente fragmento:

Ella me acaricia siempre con más ternura que nadie; no lo vais a creer, pero me parece que sus caricias son más suaves que las de mi pensamiento; ella me guía, me cuida, vela mi sueño evitándome el mal, adivina mis deseos, me arrulla con dulces canciones, se mira en mis ojos, llena de luz mi inteligencia, y, sobre todo, me enseña a amar a Dios; procura hacerme bueno, y se complace en que yo bendiga el nombre de mi papá. Es tan buena, tan buena, y me ama tanto, que ¿cómo no la he de amar? ${ }^{19}$

Y dice en el Nuevo lector colombiano: «Al estrecharme ella [la madre del narrador] en los brazos y acercarme a su pecho una sombra me cubrió los ojos; era el supremo placer que conmovía a una naturaleza virgen». ${ }^{20}$

Al hablar acá de disfrute sensual no se hace referencia a placer sexual propiamente tal, pero sí a disfrute del cuerpo, de las caricias y del contacto físico por parte de las mujeres y de los niños. Y ello es muy importante en la medida en que ese tipo de disfrute solo se expone de forma tan espontánea en esta única relación. Ello es razón para creer que estos autores, equívoca y tal vez involuntariamente, manifiestan que la experiencia original del placer físico y el enamoramiento romántico efectivamente tienen allí su modelo, y que esas mismas experiencias en la vida adulta en alguna medida pudieron replicarlo. Se hallan ejemplos en los mismos manuales en donde se insinúa que la madre y la novia juegan un papel semejante en la experiencia del sujeto adulto. En Alma española, historia de una vida ejemplar, por ejemplo, citan un poema de Jacinto Benavente:

¡Madre de mi alma! ¿No es luz de tus ojos la luz de esa estrella que como una lágrima de amor infinito en la noche tiembla? ¡Dile a la que hoy amo que no amé nunca más que a ti en la tierra, y desde que has muerto solo me ha besado la luz de esa estrella! ${ }^{21}$

De forma semejante, las expresiones de anhelo intenso por el recuerdo de la madre guardan alguna familiaridad con la desesperación de los amantes.

\footnotetext{
19 Lecturas graduadas. Libro primero (Barcelona: F.T.D., 1926), 174.

20 Roberto Cortázar et al., Nuevo lector colombiano (Bogotá: Voluntad, 1913), 179.

21 Francisco Arias, Alma española. Historia de una vida ejemplar (Barcelona: Ruiz Romero, 1939), 221.
} 
Ejemplos de este tipo de anhelo se hallan principalmente en textos cercanos al siglo XIX y comienzos del XX en los que el hijo, ya adulto, quisiera poder volver a besar a su madre muerta, o besa con impotencia los objetos que ella sostuvo mientras se imagina que ella lo abraza. En particular pareciera que para los varones, luego del disfrute de la ternura que les diera su madre en la infancia, fuera imposible expresar ese sentimiento en todas las relaciones adultas; excepto quizás, con sus hijos, pero solo en pocas ocasiones el padre se muestra como una figura tierna con ellos. Por lo tanto, la muerte de la madre significaría para el varón adulto la pérdida definitiva de uno de los escasos espacios que tuvo la ternura en su historia vital.

Adicionalmente, la imagen idealizada de la madre encarna la vuelta al paraíso perdido entre las agitaciones del mundo: «Mágico espejo de nuestras confidencias, ella [nuestra madre] nos devuelve, purificada en la diafanidad de sus aguas, la cambiante imagen de nuestra agitada existencia. Lago azul en el arenal de nuestras almas».22 Junto a la madre se acaban todos los males y peligros porque a ella se la sitúa precisamente como centro de la fortaleza defensiva que es la familia donde se han depurado los riesgos externos. Por esa misma razón, la imagen de la madre es el principal criterio de distinción de lo moralmente correcto y el freno que evita que el sujeto se entregue a las conductas peligrosas. Un ejemplo de esta situación se encuentra en la lectura «Una distribución de premios» del sacerdote jesuita Luis Coloma, citado en el texto para el grado cuarto de las Lecturas escolares. Allí, el auditorio, conformado por los padres de familia, se emociona hasta las lágrimas con la declamación de un poema a la madre por parte de uno de los niños:

Dicen que el mundo es un jardín ameno y que áspides oculta ese jardín... que hay frutos de mortal veneno, que el mar del mundo está de escollos lleno [...] ¿Y por qué estará así? Dicen que por el oro y los honores, hombres sin fe, de corazón ruin, secan el manantial de sus amores y a su Dios y a su patria son traidores. ¿Por qué serán así? Dicen que de esta vida los abrojos quieren trocar en mundanal festín; que ellos, ellos motivan tus enojos, y que ese llanto de tus dulces ojos, ¡lo causan ellos, sí! Ellos, ¡ingratos!, de pesar te llenan... ¿Seré yo también sordo a tu gemir? ¡No!... Yo no quiero frutos que envenenan, no quiero goces que a mi madre apenan. ¡No quiero ser así! ${ }^{23}$

\footnotetext{
22 Álvaro Marín y Alejandro Cano, Mi cuarto libro de lectura (Medellín: Bedout, 1944), 19.

${ }^{23}$ Lecturas escolares. Grado cuarto, 296-297.
} 
El mundo queda, por tanto, como lo diferente a la madre, y el peso simbólico de esta distinción no recae sólo en el niño, sino en la madre misma que en su papel de tal debe distinguirse como modelo moral. Asimismo, los otros amores, los que no vienen determinados por el instinto maternal y el completo desinterés, estarán bajo sospecha, por lo menos hasta que la relación con ellos se enmarque claramente en el espacio interior de la familia. Esto significa que la selección de la esposa efectivamente debe hacerse con la idea de que ella ha de ser la madre de los hijos y que, en virtud de ello su amor es familiar, o sea, amor seguro; y no amor sensual, que es transitorio e interesado.

La madre es, por lo tanto, la encarnación de la familia y la negación del mundo, y consecuentemente con ello el espacio simbólico y físico que le corresponde es el hogar, donde ella es la reina: administra y mantiene los espacios de la casa, administra la servidumbre y el dinero de las compras, recibe a los visitantes y amigos de la familia, cuida la imagen de los hijos y el esposo por medio de la pulcritud del aseo de la ropa de todos los miembros de la familia y de la casa, hace las obras de caridad con los necesitados, etcétera.

Sin embargo, ya en los manuales de finales del siglo XIX, el confinamiento al hogar, así como las misiones femeninas están siendo intensamente discutidas en los mismos libros de lectura, y es patente que todo el modelo de subjetividad femenina está en crisis. Sin embargo, como señala Pedraza: «tanto promotores como detractores de estas transformaciones [respecto de la participación de las mujeres en la vida pública] coincidieron en proteger el núcleo básico de la educación de la mujer, constituido en el siglo XIX en sus expresiones de ama de casa, madre y esposa». ${ }^{24} \mathrm{Al}$ respecto resulta muy interesante la presentación del debate que hacen en la lectura «La misión de la mujer» en Escenas de familia. Allí, una madre ilustra a su hija, en presencia de sus hijos varones, acerca del destino de la mujer. Aunque asume que la mujer debe tener los conocimientos para ser «buena esposa, buena madre y excelente ama de casa», ${ }^{25}$ señala también que las mujeres pueden ahora, además, obtener títulos profesionales:

\footnotetext{
24 Pedraza, «La "educación de las mujeres"», 72.

${ }_{25}$ Pilar Pascual de San Juan, Escenas de familia (continuación de Flora). Libro de lectura en prosa y en verso para niños y niñas (Barcelona: Imprenta Elzeveriana y Librería Camí, 1891), 218.
} 
Hubo un tiempo en que se creía que para ser mujer de su casa bastaba saber guisar, barrer, coser y remendar la ropa, y a lo sumo leer y mal escribir, y aun en época no lejana, se decía que la instrucción era perjudicial a nuestro sexo. [...] Hoy se comprende que la mujer puede y debe instruirse, cultivando las facultades de que acabo de hablar [las facultades intelectuales], sin perjuicio de ocuparse en el gobierno de la casa, lo cual ejecutará con cuánto mayor acierto cuanto sea menos ignorante. Dicen algunos que si nuestro sexo poseyese ciertos conocimientos desdeñaría las faenas y ocupaciones que nos son peculiares; pero si esto podría verificarse en alguna vanidosa, no sucedería de fijo en las de recto juicio. ${ }^{26}$

Esta madre defiende, además, la posibilidad de que las mujeres hagan carreras universitarias. Sin embargo, al final de este encomio de la instrucción femenina, el siguiente paso, la vinculación de las mujeres al mundo laboral, le causa a la autora una gran inquietud y pone en boca de su personaje la opinión según la cual «el seguir una de estas carreras y sobre todo el ejercerla es más propio del hombre que de la mujer»; ${ }^{27}$ con el argumento de que las mujeres harían una competencia innecesaria a los hombres, que ya son suficientes para atender las necesidades profesionales. Precisamente en el gesto de no dar el paso hacia el trabajo profesional y la independencia económica es en donde se manifiesta la forma de comprender el amor de la madre como sacrificio que es demandado para la defensa de la fortaleza defensiva que es la familia y la razón por la cual sostienen que la madre debe ser amada y respetada como una heroína.

Sin embargo, al considerar la transformación del modelo familiar en su conjunto, esta imagen de la subjetividad de la madre y la mujer y de los espacios que le son propios es uno de los puntos estructurales de las modificaciones que se empiezan a manifestar a lo largo del periodo acotado. Consideramos que el recuento de estas transformaciones pueden ser objeto de un artículo aparte; sin embargo, mencionamos acá sucintamente algunos de los cambios principales: en los años treinta aparecen algunas manifestaciones claras de las niñas como sujetos autónomos, principalmente en algunos manuales del periodo republicano en España; en los manuales de los años cincuenta, en los dos países, la figura de la madre se hace más

\footnotetext{
26 Pascual de San Juan, Escenas de familia, 218.

27 Pascual de San Juan, Escenas de familia, 220.
} 
juvenil y moderna y su manifestación como figura de autoridad se hace menos vigilante y aprensiva; ya en algunos textos de los años cuarenta las decisiones de la esposa se hacen más notorias al interior del hogar e incluso se muestra alguna subordinación de los maridos al criterio femenino sobre los temas afectivos y hogareños; se le otorga gran protagonismo a la madre en la administración de la casa higiénica y como soporte fundamental del mantenimiento de la salud de la familia, lo que le da relevancia a su criterio como embajadora de las declaraciones de los médicos y sacerdotes; la madre se convierte, en suma, en la principal administradora del ambiente y el cuerpo y se refuerza así como la conexión fundamental entre las políticas de gobierno del cuerpo y la familia, lo que simultáneamente la hace aparecer como más capaz de tomar decisiones autónomas.

En cuanto a los usos simbólicos que los agentes educadores hacen de la relación maternal, el apasionamiento del amor de los hijos por la madre es extrapolado principalmente a dos instituciones: la familia en su conjunto y la Patria. Con ambas la relación no es meramente admiración y agradecimiento, sino apasionamiento amoroso, que puede llegar a ser ciego y violento si lo requieren las circunstancias; así es mostrado en los relatos heroicos en donde se trata de salvar a cualquiera de las dos instituciones. Se trata, en tales casos, de sacrificios en donde la sola consideración de un cálculo de beneficios o perjuicios a favor del individuo se vería como culpable. El sujeto debe reaccionar inmediatamente sin guardarse nada y el que no lo hace es irremediablemente un cobarde y un traidor. El ejemplo más frecuente, repetido en los textos de ambos países, es el del sacrificio que hace Guillermo Tell por liberar a su pueblo de un tirano, pero también se narran ejemplos propios de cada país. En el caso español, los relatos de Guzmán el Bueno y el general Moscardó, que sacrifican la vida de sus hijos por defender su patria; y en el caso colombiano se narra en varios textos, e incluso en el Himno Nacional, la autoinmolación de Antonio Ricaurte en la Guerra de Independencia, que se sacrificó para evitar que los españoles se apoderaran de unas municiones.

Aún por encima de la patria, se postulan otras madres a las que se debe amar con el mismo impulso pasional y que aman a los hombres de vuelta: la Virgen María y la Naturaleza, lo cual permite completar un verdadero sistema de amor desinteresado en toda la realidad; sentimiento que, en últimas, constituye su clave profunda y el motivo de su orden estructural. El bien, la alegría, el gozo son, en consecuencia, expresiones de la realidad maternal 
del cosmos, el aspecto visible de la bondad divina. El mal, por su parte, no proviene de Dios, sino del egoísmo, pero su solución está en la virtud de la caridad, que es considerada como una madre:

¡Oh caridad sublime! ¡Oh inspiración del cielo! ¡Oh rayo que desciendes de la sagrada Cruz y esparces por la tierra suavísimo consuelo, resignación y luz! ¡Tú riges los impulsos del corazón humano! Tú calmas de la vida la ronca tempestad. Tú lloras con el triste y apoyas al anciano, tú amparas la orfandad. [...] Recoges el aliento postrer del moribundo, vas como amante madre, del desdichado en pos, por ti los hombres mueren sin renegar del mundo, con su esperanza en Dios. ${ }^{28}$

En consecuencia, la solución a las penurias de los pobres es, en este modelo patriarcal, el complejo sistema de la caridad en el cual la Iglesia Católica cumple la misión protectora y dadivosa de la madre que se ocupa del bienestar de sus hijos más necesitados.

\section{CONCLUSIONES}

Este breve recorrido por las diferentes extrapolaciones del amor maternal permite recalcar los diferentes contenidos con los que simbólicamente se recargó este concepto en la formación de la subjetividad, y hasta qué punto podría resultar subversivo el posible rechazo de la maternidad y de la familia en general. Asimismo, señala la intensidad y complejidad de las sujeciones culturales que definen la relación madre e hijo y que ponen sobre los hombros de la mujer el deber de ser el pilar simbólico de la moral y de la estabilidad social; un deber que se le impone como honroso y sublime y como causa de su realización existencial, pero por cuyo cumplimiento se le demanda toda su vida. Aunque son notorias, a lo largo del periodo, algunas variaciones sobre las condiciones de este sacrificio que magnifican la posición de la mujer y parecen otorgarle algún grado de empoderamiento y relevancia social, de todos modos no se halló que se cuestionara aún que el ámbito femenino por excelencia era la administración del hogar y que la definición existencial de la feminidad estuviera en la maternidad. Sin embargo, el presente artículo deja abiertos un par de temas en relación con la

${ }^{28}$ Constanza Sanín de Díaz, El lector colombiano. Número dos (Bogotá: Librería colombiana Camacho Roldán y Cía. S.A., 1911), 260. 
educación de los afectos al interior de la familia en los que estos mismos libros de lectura pueden ofrecer pistas interesantes al investigador: en primer lugar, el tratamiento de la estructura de la relación afectiva entre el padre y los hijos y, en segundo lugar, la estructura de la relación afectiva de los esposos entre sí.

En cuanto a la educación de los afectos, se ha hecho patente que los agentes educadores buscaron que la relación madre hijo tuviera un componente pasional que, por extensión, convirtiera en una pasión entrañable la relación con la familia, con la patria y sus instituciones. Se trata de una trama compleja de técnicas para gobernar a los sujetos a través de la administración de sus afectos. Dada la variedad y la complejidad de estos mecanismos y estrategias de entrenamiento de los sentimientos podemos hablar de que estamos ante la operación de un dispositivo emocional que pretendió enmarcar normativamente las formas de sentir y de relacionarse socialmente. 


\section{Nota sobre el autor}

Federico Guillermo SERrano López es filósofo y magíster en filosofía de la Universidad Nacional de Colombia. Se doctoró en el programa de pensamiento español y latinoamericano de la Universidad Autónoma de Madrid. Ha sido profesor del Departamento de Filosofía de la Pontificia Universidad Javeriana y de la Escuela de Ciencias Humanas de la Universidad Colegio Mayor de Nuestra Señora del Rosario. Actualmente es profesor e investigador de la Universidad Tecnológica de Bolívar, donde a la fecha es el decano de la Facultad de Ciencias Sociales y Humanas. Su trabajo como investigador se ha orientado a la filosofía del arte y a la filosofía e historia de las subjetividades. Dentro de estos campos, en los últimos años su interés se ha centrado en la historia de la preparación para la sexualidad en el ámbito escolar en la primera mitad del siglo XX en España y en Colombia. 